\title{
Fall-induced hospital-treated traumatic brain injuries among elderly Finns in 1970-2017
}

Pekka Kannus MD, $\mathrm{PhD}^{1-3}$, Seppo Niemi1 ${ }^{1}$, Jari Parkkari MD, $\mathrm{PhD}^{2}$, Ville Mattila MD, $\mathrm{PhD}^{3}$, Harri Sievänen ScD 1

1 Injury and Osteoporosis Research Center, UKK Institute for Health Promotion Research, Tampere, Finland

2 Tampere Research Center of Sports Medicine, UKK Institute for Health Promotion Research, Tampere, Finland

3 Medical School, Tampere University, and Department of Orthopedics and Traumatology, Tampere University Hospital, Tampere, Finland

Running title: Traumatic brain injury in elderly Finns

Correspondence to:

Prof. Pekka Kannus, MD, PhD

UKK Institute, P.O. Box 30,

FIN-33501 Tampere, FINLAND

phone: +358-3-282-9111

fax: $\quad+358-3-282-9200$

e-mail: Pekka.Kannus@ukkinstituutti.fi 


\section{Abstract}

Background: Fall-induced traumatic brain injuries (TBI) of elderly adults are a major public health concern.

Methods: We determined the current trends in the absolute number and incidence (per 100,000 persons) of severe fall-induced TBI among 80 -year-old or older Finns by taking into account all persons who were admitted to Finnish hospitals for primary treatment of such injury between 1970 and 2017.

Results: The total number of hospitalized older Finns with a fall-induced TBI increased considerably between the years 1970 and 2017, from 60 (women) and 25 (men) in 1970 to 1622 (women) and 991 (men) in 2017. The age-adjusted incidence of TBI (per 100,000 persons) also showed a clear increase from 1970 to 2017: from 167.9 to 800.4 in women (377\% increase), and from 176.8 to 927.3 in men (424\% increase). If this trend in the age-adjusted incidence of hospitaltreated TBI continues, and the size of the 80-year-old or older Finnish population increases as predicted (from 0.29 million in 2017 to 0.49 million in 2030), the number of these severe injuries among 80-year-old or older Finns will be approximately 1.8 times higher in 2030 (4811 injuries) compared with 2613 injuries in 2017.

Conclusions: The number and age-adjusted incidence of fall-induced hospital-treated TBI among elderly Finns increased considerably between 1970 and 2017. Wide-scale fall and injury prevention measures are urgently needed, because further aging of the population is likely to worsen the problem in the near future.

Key words: Fall-induced Traumatic Brain Injury - Elderly Finnish Persons - Secular Trends 


\section{Introduction}

Traumatic brain injury (TBI) is a major cause of hospitalization, disability and death worldwide (1-5). Younger people usually receive a TBI in sports activities, motor-vehicle crashes or assaults, while among elderly people a simple fall is clearly the most common cause of the TBI (1-10). In long-term care facilities, head impact occurs in surprisingly many fall incidents, in one-third of all falls (11).

As such, falls and related injuries are a major public health concern, especially in contemporary societies that have aging populations $(2,3,9)$. As the number of elderly persons in these populations continues to increase, the number of injuries will also rise.

About $30 \%$ of older adults living in the community and over $50 \%$ of those living in institutions fall every year, and about $50 \%$ of those who fall do so repeatedly (2). Not all falls are injurious, but 4$5 \%$ of them result in a fracture, and other serious injuries, such as TBI, severe lacerations and serious soft tissue injuries, occur in 5-11\% of falls $(2,3,4,7,8-10)$. Of these categories, a fall-induced TBI is the most severe (life-threatening) condition.

Previously we reported that the number and incidence of fall-induced hospital-treated TBI in Finnish older adults 80 years of age or older have shown an increasing trend since 1970s (12). The objective of this study was to follow this high-risk population to the end of 2017 to assess the most recent changes in the risk of this severe and disabling injury. These statistics will benefit all parties (health care professionals, politicians) related to falls and injury prevention of older adults. Understanding the epidemiologic trends in elderly people's TBI will help in organizing and optimizing the preventive work and its resources. 


\section{Materials and Methods}

In accord with other epidemiologic studies $(2,12,13)$, we defined a fall-induced TBI as a head injury that occurred as a consequence of a fall from standing height of $1 \mathrm{~m}$ or less and resulted in hospitalization of the victim and then collected from the National Hospital Discharge Register (NHDR) all Finnish persons 80 years of age or older who were admitted to our hospitals from 1970 to 2017 for primary treatment of such injury. Traffic accidents and other high energy trauma were excluded, as were cases with codes identifying trauma sequelae and orthopedic aftercare.

The Finnish NHDR (established in 1967) is operated by the National Institute of Health and Welfare (Helsinki, Finland). It is the oldest nationwide discharge register in the world, and the data provided are well suited for epidemiologic analyses. This statutory, computer-based register is well validated covering acute injuries in the population adequately (annual coverage of injuries is $\geq$ $90 \%$ ) and recording them accurately (annual accuracy of injury diagnoses is also $\geq 90 \%$ ). This concerns especially severe injuries with clear-cut diagnoses, such as TBI $(14,15)$.

Between 1970 and 2017, the Finnish NHDR has used the eighth, ninth, and tenth revisions of the International Classification of Diseases: ICD-8 (1970-1986), ICD-9 (1987-1995), and ICD-10 (1996-2017). The used diagnosis code classes for the TBI were: 800-804 and 850-854 (ICD-8); 800-803 and 850-854 (ICD-9); and S02, S06, S07 and S09 (ICD-10).

The annual midyear population figures in 1970-2017 and the population prediction until the year 2030 were taken from the Official Statistics of Finland $(16,17)$. In this statutory, computer-based register (The Official Population Register of Finland), every Finn is registered by his or her personal identification number. The register is quality controlled continuously and updated by Statistics Finland, the Central Statistical Office of Finland. 
Age-adjusted and age-specific incidences of hospital-treated TBI were calculated for both sexes and were expressed as the number of cases per 100,000 adults aged 80 years or older per year. The age adjustment was performed by direct standardization using the mean $80+$ population in $1970-2017$ as the standard population. Calculations for the age-specific incidences were done in 5-year age groups (80-84, 85-89, and $\geq 90$ years).

In each of the above noted age groups, the future incidence prediction was assessed using a linear regression model, and then, within each age and sex group, the predicted absolute number of hospital-treated TBIs in 2030 was obtained by multiplying the incidence by the estimated number of inhabitants. This estimation was obtained from the Finnish Population Projections 2018-2030 (17).

The study consisted of the entire Finnish population (4.6 million people in 1970 with a gradual growth to 5.5 million in 2017). Thus, the given absolute numbers and incidence rates of the hospital-treated TBI among 80-year-old or older Finns were not cohort-based estimates but actual results in the respective total population, and therefore, this study, in full agreement with our previous epidemiologic investigations $(2,12,13)$, did not use statistical analyses with probability values and confidence intervals characteristically needed in cohort or sample-based estimations with sampling variability. 


\section{Results}

The total number of hospital-treated older Finns with a fall-induced TBI increased considerably between the years 1970 and 2017, from 60 (women) and 25 (men) in 1970 to 1622 (women) and 991 (men) in 2017 (Figure 1A). The age-adjusted incidence of TBI (per 100,000 persons) also showed a clear increase from 1970 to 2017: from 167.9 to 800.4 in women (377\% increase), and from 176.8 to 927.3 in men (424\% increase) (Figure 1B).

In women, the age-specific hospital-treated TBI incidence rates (per 100,000 persons) in the age groups of 80-84, 85-89, and 90 years or older in 1970 vs. 2017 were 170, 171 and 151 vs. 604, 944 and 1311, respectively (Figure 2A). In men, these rates were 160, 56 and 681 vs. 729, 1146 and 1704 (Figure 2B).

If the above noted trend in the age-adjusted TBI incidence rates continues, and the size of the 80year-old or older Finnish population increases as predicted (from 0.29 million in 2017 to 0.49 million in 2030), the number of fall-induced hospital-treated TBI among 80-year-old or older Finns will be approximately 1.8 times higher in 2030 (4811 injuries) than 2017 (2613 injuries) (Figure 3). 


\section{Discussion}

This 47-year follow-up study shows that the number and age-adjusted incidence (i.e., average individual risk) of fall-induced hospital-treated TBI in Finnish men and women aged 80 years or older increased considerably during 1970-2017. Compared to the data in our previous study (12), the alarming rise has continued (Figure 1).

Our findings are in line with other recent observations on fall-induced severe TBI among elderly adults (1-10), but the exact reasons for the ongoing increase are largely unknown. In other words, we do not know whether the increase in fall-induced TBI is related to an increase in falls, an increase in TBI after a fall, or both. Today elderly people, or at least the frailest part of them, may fall more often and more seriously than their predecessors as they live long with many chronic diseases and disorders $(1,2,12,18-21)$. Also, some strong external risk factors for falling, such as polypharmacy, may have become more common among elderly adults $(1,2,18)$, and additionally, changes in living arrangements; impaired balance, muscle strength and vision; sensory neuropathy; alcohol drinking; poor nutrition; and increased use of anticoagulants may have contributed $(12,18-22)$.

The strengths of this epidemiologic secular trend analysis include unchanged TBI definition, a population-based complete, accurate and current database, and exceptionally long follow-up. The limitations include the lack of information on non-hospitalized TBI victims and reasons and risk factors for falls and subsequent injuries (12). In the USA, approximately one-third of older adults with TBI are hospitalized (5). Although our TBI population consisted of the oldest old with high probability for hospital admission, the unknown proportion of nonhospitalized patients might refer to possible secular changes in the hospitalization policy of 
the TBI victims. We see that for two reasons this cannot well explain our continuously and steeply risen numbers in 1970-2017. Firstly, in head injuries nothing else than the condition of the patient has always dictated the decision for hospitalization. In other words, according to the long-term clinical traumatologic experience in our research team, the indications for hospital admission of the TBI persons have not changed by time. Secondly, our previous study concerning fall-induced cervical spine injuries of older adults between 1970 and 2011 (fracture, cord injury or their combination) showed a similarly drastic rise in the number and incidence of the victims and all these patients have always been hospitalized (23).

Taken together, the number and age-adjusted incidence of fall-induced TBI among older Finns increased steeply between 1970 and 2017 and rapid aging of the population is likely to exacerbate the problem in the near future. Further studies are needed to better understand the reasons for the increase so that effective interventions for falls and injury prevention can be initiated. Current evidence suggests that falls prevention programs among older adults have potential to reduce falls, serious fall-induced injuries, and subsequent emergency department visits, hospitalizations, nursing home placements, functional decline and mortality $(2,18,22,23)$. Multifactorial interventions aimed at reducing the number of falls of elderly persons by simultaneously modifying many of the predisposing and situational risk factors for falls have shown promising results $(2,22,24,25)$. Also, single interventions, such as strength and balance training, reduction in psychotropic medication, correction of visual impairment, home-hazard assessment and modification, and gait-stabilizing anti-slip devices, can be effective $(21,22,26,27)$. 


\section{Funding}

This study was funded by the Comparative Research Funding of the Pirkanmaa Hospital District, Tampere, Finland (grant no 9V015). The organization had no involvement in the (1) study design;

(2) collection, analysis and interpretation of data; (3) writing of the manuscript; and (4) decision to submit the manuscript for publication.

\section{Acknowledgements}

The authors thank the National Institute of Health and Welfare and the Finnish Ministry of Social Affairs and Health for cooperation and help in conducting the study.

\section{Conflict of interest}

The authors have no conflicts of interest. 


\section{References}

1. Harvey LA, Close JC. Traumatic brain injury in older adults: characteristics, causes and consequences. Injury 2012; 43:1821-1826. doi:10.1016/j.injury.2012.07.188

2. Kannus P, Parkkari J, Koskinen S, et al. Fall-induced injuries and deaths among older adults. JAMA 1999;281:1895-1899.

3. Hartholt KA, Van Lieshout EM, Polinder S, Panneman MJ, Van der Cammen TJ, Patka P. Rapid increase in hospitalizations resulting from fall-related traumatic head injury in older adults in the Netherlands 1986-2008. J Neurotrauma 2011;28:739-744. doi:10.1089/neu.2010.1488

4. Fu TS, Jing R, McFaull SR, Cusimano MD. Recent trends in hospitalization and in-hospital mortality associated with traumatic brain injury in Canada: A nationwide, population-based study. J Trauma Acute Care Surg 2015;79:449-454.

5. Taylor CA, Bell JM, Breiding MJ, Xu L. Traumatic brain injury-related emergency department visits, hospitalizations, and deaths - United States, 2007 and 2013. MMWR Surveill Summ 2017;66:1-16. doi:10.15585/mmwr.ss6609a1

6. Sung KC, Liang FW, Cheng TJ, Lu TH, Kawachi I. Trends in unintentional fall related traumatic brain injury death rates in older adults in the United States, 1980-2010: a joinpoint analysis. J Neurotrauma 2015;32:1078-1082. doi:10.1089/neu.2014.3509 
7. Buchele G, Rapp K, König HH, et al. The risk of hospital admission due to traumatic brain injury is increased in older persons with severe functional limitations. J Am Med Dir Assoc 2016;17:609612. doi:10.1016/j.jamda.2016.02.032

8. Harvey LA, Mitchell R, Brodaty H, Draper B, Close JC. Comparison of fall-related traumatic brain injury in residential age care and community-dwelling older people: a population-based study. Australas J Ageing 2017;36:144-150. doi:10.1111/ajag.12422

9. Gardner RC, Dams-O’Connor K, Morrissey MR, Manley GT. Geriatric traumatic brain injury: epidemiology, outcomes, knowledge caps, and future directions. J Neurotrauma 2018 Feb 15. doi: 10.1089/neu.2017.5371

10. Fu WW, Fu TS, Jing R, McFaull SR, Cusimano MD. Predictors of falls and mortality among elderly adults with traumatic brain injury: a nationwide, population-based study. PLoS One 2017;12(4):e0175868. doi:10.1371/journal.pone.0175868

11. Yang Y, Mackey DC, Liu-Ambrose T, Leung PM, Feldman F, Robinovitch SN. Clinical risk factors for head impact during falls in older adults: a prospective cohort study in long-term care. J Head Trauma Rehabil 2017;32:168-177. doi:10.1097/HTR.0000000000000257

12. Korhonen N, Niemi S, Parkkari J, Sievänen H, Kannus P. Incidence of fall-related traumatic brain injury among older Finnish adults between 1970 and 2011. JAMA 2013;309:1891-1892. doi: 10.1001/jama.2013.3356 
13. Kannus P, Niemi S, Sievänen H, Parkkari J. Stabilized incidence in proximal humeral fractures of elderly women: nationswide statistics from Finland in 1970-2015. J Gerontol A Biol Sci Med Sci 2017;72:1390-1393. doi:10.1093/gerona/glx073

14. Mattila VM, Sillanpää P, Iivonen T, Parkkari J, Kannus P, Pihlajamäki H. Coverage and accuracy of cruciate ligament injury in the Finnish National Hospital Discharge Register. Injury 2008;39:1373-1376. doi:10.1016/j.injury.2008.05.007

15. Sund R. Quality of the Finnish Hospital Discharge Register: a systematic review. Scand J Public Health 2012;40:505-515. doi:10.1177/1403494812456637

16. Official Statistics of Finland. Population Structure 1970-2017. Statistics Finland, Helsinki, Finland, 2018.

17. Official Statistics of Finland. Population Projection by Municipalities 2018-2030. Statistics Finland, Helsinki, Finland 2017.

18. Tinetti ME, Kumar C. The patient who falls: “It’s always a trade-off”. JAMA 2010;303:258266. doi:10.1001/jama.2009.2024

19. Welmer AK, Rizzuto D, Laukka EJ, Johnell K, Fratiglioni L. Cognitive and physical function in relation to the risk of injurious falls in older adults: a population-based study. J Gerontol A Biol Sci Med Sci 2017;72:669-675. doi:10.1093/gerona/glw141 
20. Ferrucci L, Cooper R, Shardell M, Simonsick EM, Schrack JA, Kuh D. Age-related change in mobility: perspectives from life course epidemiology and geroscience. J Gerontol A Biol Sci Med Sci 2016;71(9):1184-1194. doi:10.1093/gerona/glw043

21. Uusi-Rasi K, Patil R, Karinkanta S, Kannus P, Tokola K, Lamberg-Allardt C, Sievänen H. A 2Year Follow-Up After a 2-Year RCT with Vitamin D and Exercise: Effects on Falls, Injurious Falls and Physical Functioning Among Older Women. J Gerontol A Biol Sci Med Sci 2017;72:12391245. doi:10.1093/gerona/glx044

22. Panel on Prevention of Falls in Older Persons, American Geriatrics Society and British Geriatrics Society. Summary of the Updated American Geriatrics Society/British Geriatrics Society Clinical Practice Guideline for Prevention of Falls in Older Persons. J Am Geriatr Soc 2011;59:148-157. doi:10.1111/j.1532-5415.2010.03234.x

23. Korhonen N, Kannus P, Niemi S, Parkkari J, Sievänen H. Rapid increase in fall-induced cervical spine injuries among older Finnish adults between 1970 and 2011. Age Ageing 2014; 43:567-571. doi: 10.1093/ageing/afu060

24. Palvanen M, Kannus P, Piirtola M, Niemi S, Parkkari J, Järvinen M. Effectiveness of the Chaos Falls Clinic in preventing falls and injuries of home-dwelling older adults: a randomised controlled trial. Injury 2014;45:265-271. doi: 10.1016/j.injury.2013.03.010

25. Hopewell S, Copsey B, Nicolson P, Adedire B, Boniface G, Lamb S. Multifactorial interventions for preventing falls in older people living in the community: a systematic review and meta-analysis of 41 trials and almost 20000 participants. Br J Sports Med 2019; epubl. doi: 10.1136/bjsports-2019-100732 
26. Sherrington C, Fairhall NJ, Wallbank GK, Tiedemann A, Michaleff ZA, Howard K, Clemson L, Hopewell S, Lamb SE. Exercise for preventing falls in older people living in the community. Cochrane Database Syst Rev 2019 Jan 31;1:CD012424. doi: 10.1002/14651858

27. Tricco AC, Thomas SM, Veroniki AA, Hamid JS, Cogo E, Strifler L et al. Comparisons of interventions for preventing falls in older adults: A systematic review and meta-analysis. JAMA 2017;318:1687-1699. doi: 10.1001/jama.2017.15006 

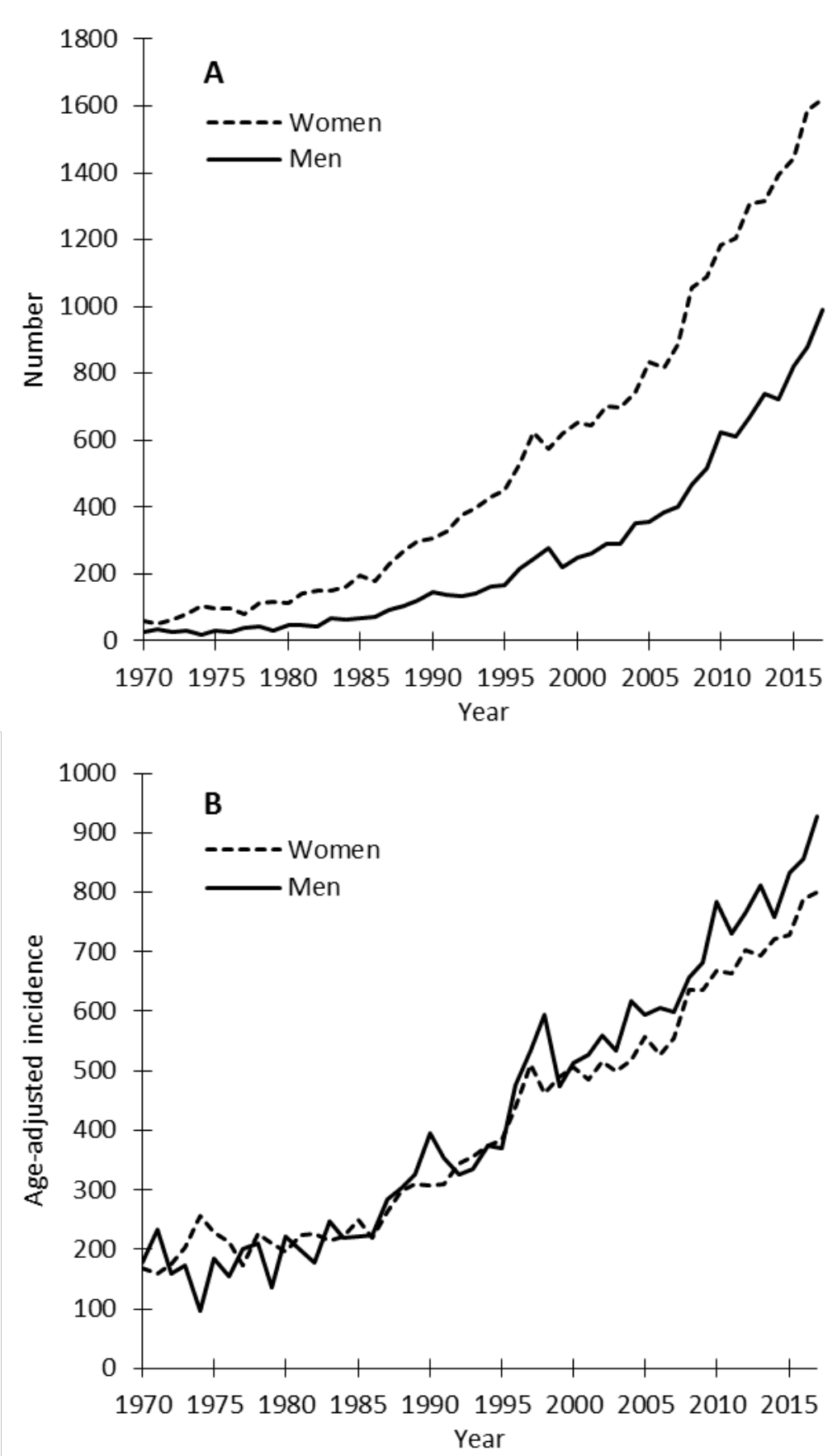

Figure 1. Fall-induced hospital-treated traumatic brain injuries in Finnish women and men 80 years or older between 1970 and 2017. A) Number B) Age-adjusted incidence (per 100,000). 

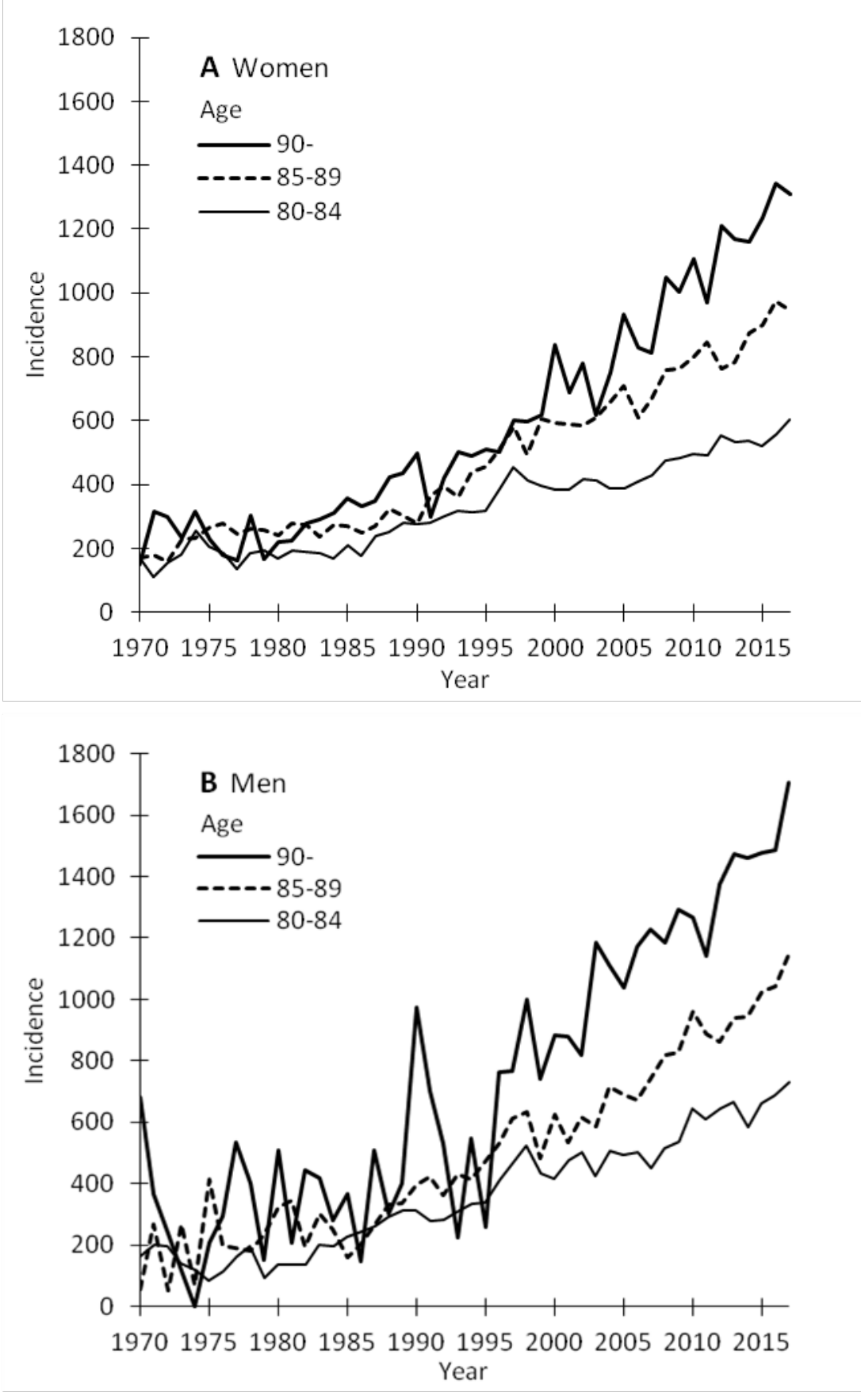

Figure 2. Age-specific incidence (per 100,000) of fall-induced hospital-treated traumatic brain injuries in Finnish women and men 80 years or older between 1970 and 2017. A) Women B) Men. 


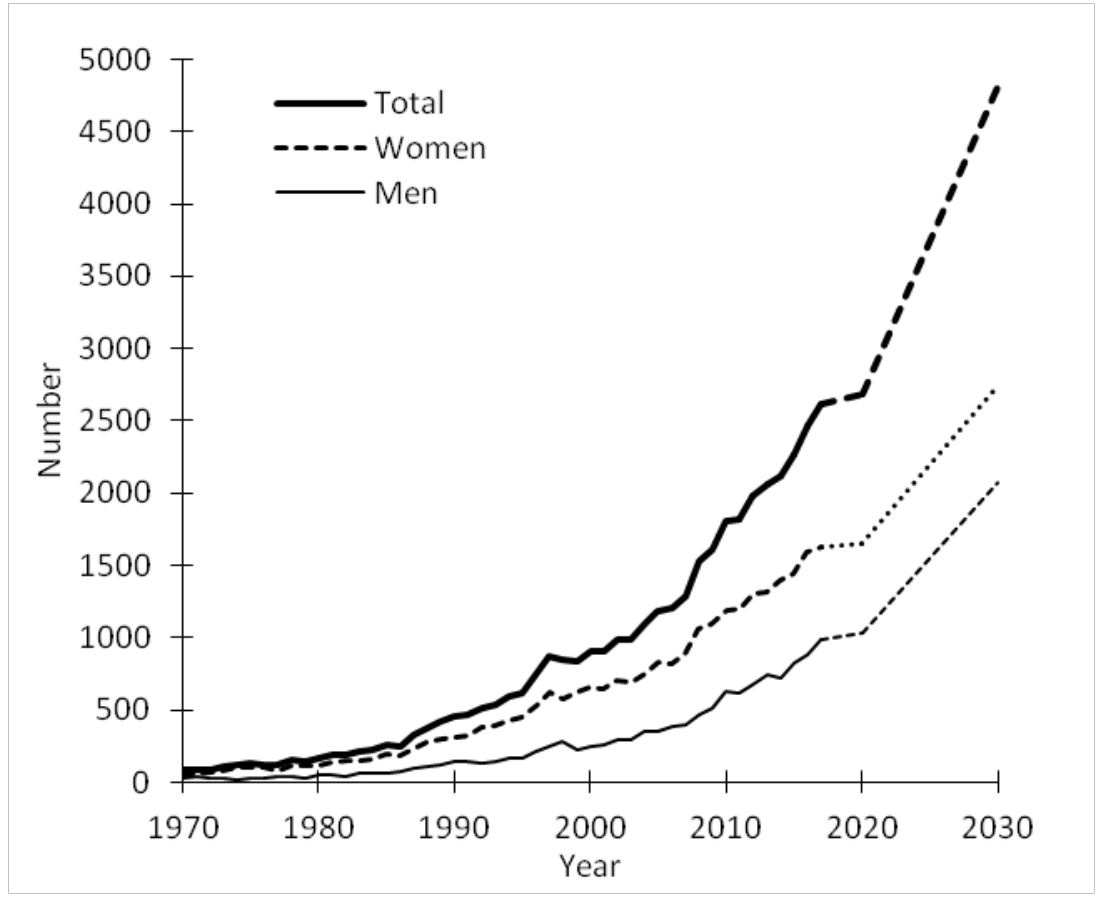

Figure 3. Actual and predicted numbers of fall-induced hospital-treated traumatic brain injuries (TBI) in elderly Finns 80 years of age or older between 1970 and 2030. The prediction part of each curve (2018-2030) denotes to a TBI development-model in which the age-adjusted incidence of injury will increase with a rate observed in 1970-2017 (see Figure 1B). The size of the 80-year-old or older Finnish population is, in turn, predicted to increase from 0.29 million in 2017 to 0.49 million in 2030. 